\title{
Deformation and fracture behavior of in-situ Ti composites reinforced with TiB/nano-sized particles
}

\author{
Yuanfei Han ${ }^{a^{*}}$, Xianglong Sun ${ }^{\mathrm{a}}$, Pinwang Liü ${ }^{\mathrm{a}}$, Guangfa Huang ${ }^{\mathrm{a}}$, Lv Xiao ${ }^{\mathrm{c}}$, Weijie Lu ${ }^{\mathrm{a}, \mathrm{b}^{*}}$ \\ ${ }^{\mathrm{a}}$ State Key Laboratory of Metal Matrix Composites, School of Materials Science and Engineering, Shanghai Jiao Tong University, Shanghai 200240, China
}

${ }^{\mathrm{b}}$ Shanghai Key Laboratory of Advanced High Temperature Materials and Precision Forming,

Shanghai 200240, China

'Shanghai Spaceflight Precision Machinery Institute, China Aerospace Science and Technology Corporation, Shanghai 201600, China

Abstract: The hot deformation and fracture behavior of TiB/nano-sized particulate reinforced titanium matrix composites were investigated. The effect of reinforcement contents and initial structures on the isothermal deformation and fracture characteristic were investigated through microstructure analysis, tensile tests and crack propagation tests. It was found that the optimal working parameters for Ti composites is determined at $900-950^{\circ} \mathrm{C} / 0.01-0.1 \mathrm{~s}^{-1}$, which is associated with the continuous dynamic recrystallization of primary a grains and dynamic globularization of lamellar $a$. The necklace recrystallization was observed in $\beta$ phase region, and the instability mechanisms include inhomogeneous deformation and breaking or debonding of TiB whiskers. Additionally, the addition of reinforcements refines a phases, decreasing the lamellar a width. The aspect ratio of TiB is much higher with the increase of reinforcement content. Higher content ( 2.5 vol. \% and 5 vol. \%) brings about more broken reinforcements and defects, which result in brittle fracture in Ti composite. Reinforcements and defects are believed to be the key factors to determine the crack propagation. Intergranular cracking is the main cracking way in the region where there are few reinforcements. Defects caused by fractured TiB play a dominant role in diverting intergranular cracking to transgranular cracking.

Key words: Hot deformation, dynamic globularization, dynamic recrystallization, Titanium matrix composites

* Corresponding author.

Email address: hyuf1@sjtu.edu.cn (Yuanfei Han), luweijie@sjtu.edu.cn (Weijie Lu).

\section{Introduction}

Titanium matrix composites (TMCs) are attractive for various applications, including aerospace, automotive and weapons, due to their high strength-to density ratio, excellent high temperature durability and good high temperature resistance ${ }^{[1-3]}$. However, TMCs reinforced with hard ceramic demonstrate very low room-temperature ductility, which is inadmissible for structural materials ${ }^{[4-5]}$. In the previous studies on in situ TMCs, hot deformation or warm working of TMCs can obtain some increase in the low ductility ${ }^{[6]}$, but TMCs are more difficult to process compared with the traditional titanium alloy ${ }^{[7]}$. Therefore, comprehensive investigations of the hot deformation and fracture characteristic of TMCs are still needed to determine the optimal conditions of the hot working process.

It is obvious that reinforcement play an important role in the deformation of $\mathrm{TMCs}$. Until now, lots of ceramic, such as $\mathrm{TiB}, \mathrm{TiC}, \mathrm{TiB}_{2}, \mathrm{Ti}_{5} \mathrm{Si} \mathrm{H}_{3}, \mathrm{Al}_{2} \mathrm{O}_{3}$, $\mathrm{Ti}_{2} \mathrm{AlC}_{\mathrm{C}} \mathrm{SiC}, \mathrm{have}$ been proposed as the appropriate reinforcement ${ }^{[8]}$. Among all kinds of reinforcements, TiB has been extensively considered as the best reinforcement in titanium matrix due to the high Young's modulus of 550GPa, the coefficient thermal expansion of $8.6 \times 10^{-6} / \mathrm{K}$, which is quite near to that of titanium, $9.6 \times 10^{-6} / \mathrm{K}$, a low density and excellent

(C) The Authors, published by EDP Sciences. This is an open access article distributed under the terms of the Creative Commons Attribution License 4.0 (http://creativecommons.org/licenses/by/4.0/). 
interfacial bonding with the metal matrix. Previous studies by the authors ${ }^{[9]}$ have shown that refine the initial structure significantly affects the deformation behavior and microstructural characteristic during the hot working of TMCs. The addition of rare earth element has been verified to be able to decrease the oxygen content, and refine the grain size, enhance the thermal stability and assist in the improvement of service temperature for TMCs. The rare earth elements easily react with oxygen resulting in the formation of hard and thermal stability nano-size rare earth oxides, which can contribute to the high temperature mechanical properties of TMCs ${ }^{[10,11]}$. Therefore, TMCs reinforced with TiB and nano-sized particles are promising in obtaining good overall mechanical properties, particularly after hot deformation.

In the present study, the deformation and fracture behavior of in situ Ti composite reinforced with TiB and nano-sized particles with different initial structures through isothermal deformation were studied. Additionally, the effect of reinforcements on the fracture behavior of Ti composite was investigated.

\section{Material and experiments}

2.1 Initial Materials

In the present work, $\mathrm{TiB}+\mathrm{La}_{2} \mathrm{O}_{3} / \mathrm{Ti}$ composite were in situ synthesized by casting and hot forging. The nominal composition of the metal matrix is Ti-6.6 Al-4.6Sn-4.6Zr0.9 Nb-1.0Mo-0.32Si. TiB whisker and $\mathrm{La}_{2} \mathrm{O}_{3}$ particles were in situ synthesized according to the reaction: $12 \mathrm{Ti}+\mathrm{LaB}_{6}+3[\mathrm{O}]=12 \mathrm{TiB}^{\mathrm{L}} \mathrm{La} \mathrm{O}_{2} \mathrm{O}_{3}$. $\phi 580 \mathrm{~mm}$ cast ingot was fabricated by vacuum consumable electrode furnace, and consequently hot-forged to $\$ 280 \mathrm{~mm}$ in the $\beta$ phase region (above the $\beta$ transformation temperature of $1040^{\circ} \mathrm{C}$ ). Finally, the rods were hot forged to $\$ 70 \mathrm{~mm}$ in $\alpha+\beta$ phase region. The uniform refined microstructure could be obtained. Fig.1 shows the optical microstructure and SEM image of the as-received forged $\mathrm{TiB}+\mathrm{La}_{2} \mathrm{O}_{3}$ hybrid reinforced TMCs. The initial microstructure consisted of approximately $85 \%$ elongated a phases, and TiB fibers were oriented along the hot forging direction. It is about $2 \mu \mathrm{m}$ in thickness, and the $\mathrm{La}_{2} \mathrm{O}_{3}$ particles were $200-700 \mathrm{~nm}$ in diameter, which were distributed uniform in the matrix of Ti composite.
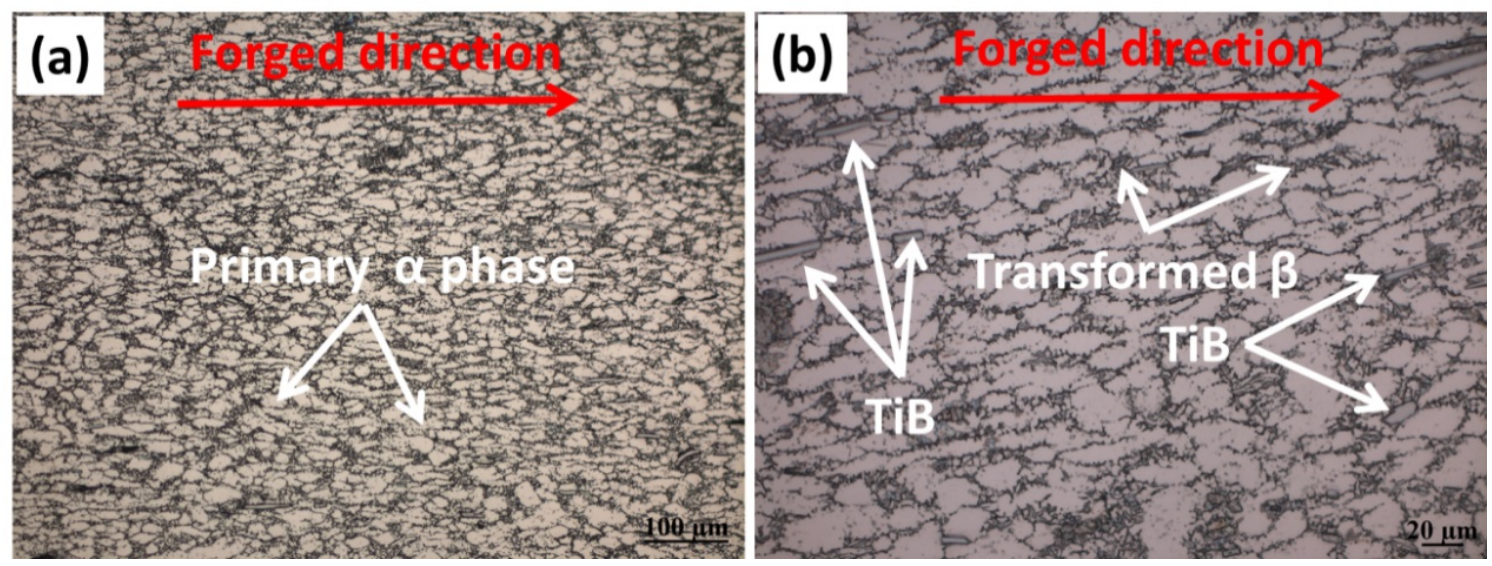

Fig.1 Initial microstructure of the as-received Ti composite (a) low magnification (b) high magnification

2.2 Hot deformation

The isothermal deformation was carried out on the Gleeble- 3500 therma0-mechanical simulator with Ar as the protection gas. $\$ 8 \mathrm{~mm} \times 12 \mathrm{~mm}$ cylindrical specimens were prepared by electro-discharge machining from the $\phi 70 \mathrm{~mm}$ forged billet with the axis parallel to the forged direction. Two heat treatment routes were designed to disclose the initial structure effect on the deformation behavior. Hot deformation were perform at the temperature of $850^{\circ} \mathrm{C}-1100^{\circ} \mathrm{C}$ and strain rate of $0.001-1 \mathrm{~s}^{-1}$. Graphite foils were placed between the specimens and anvils to minimize the friction effects during deformation. Previous work have been obtain several good results that the dynamic recrystallization occur when the high reduction of the specimens were $60 \%-70 \%$. We designed a reduction of $60 \%$ for this study, which was equal to the true strain of 0.92. All deformed specimens should be immediately water quenched to keep the deformed structure in a high temperature. 
Microstructural observation were performed by optical microscope (OM), Sirion 200 scanning electron microscope (SEM), JEM 2100 transmission electron microscopy (TEM) and NOVA NanoSEM 230 electron backscatter diffraction (EBSD). For OM and SEM observations, the specimens were sectioned parallel to the hot deformed direction, and the specimens were embedded, mechanically polished and etched with a solution of $7 \% \mathrm{HF}, 20 \% \mathrm{HNO}$ and $73 \% \mathrm{H} 2 \mathrm{O}$ (in volume). TEM specimens were cut from the center of the samples and mechanically ground to $\sim 50 \mu \mathrm{m}$. The electron transparent regions were obtained in the disk specimens by twin-jet electro polishing in a solution with $6 \% \mathrm{HClO} 4,64 \% \mathrm{CH} 3 \mathrm{OH}$ and $30 \% \mathrm{C} 4 \mathrm{H} 9 \mathrm{OH}$ (in volume) at $\sim 40^{\circ} \mathrm{C}$ and a voltage of $35 \mathrm{~V}$. EBSD specimens were prepared by grinding, polishing and vibration polishing with a colloidal silica suspension. The scanning step for EBSD was $0.5 \mu \mathrm{m}$, and the TSL OIM 6 software was used for the data analysis. The phase identify were analyzed through $\mathrm{X}$ ray diffraction (XRD, D-max $2550 \mathrm{~V}$ ) with Cu Ka radiation, operation at $35 \mathrm{KV}$ and $200 \mathrm{~mA}$. The data were collected for a $2 \theta$ angle ranging from $20^{\circ}$ to $90^{\circ}$ with a scan rate of $0.5^{\circ} / \mathrm{min}-1$ and a step size of $0.02^{\circ}$.

\section{Results}

3.1 Phase identification and microstructure

Fig.1 shows X-ray diffraction patterns for the deformed TMCs. It is indicating that the phases present are $a-\mathrm{Ti}$, TiB and $\mathrm{La}_{2} \mathrm{O}_{3}$. The result of X-ray diffraction analysis confirms that the $\mathrm{TiB}+\mathrm{La}_{2} \mathrm{O}_{3} / \mathrm{Ti}$ composite could be fabricated by the common casting technique, which was using the chemical reaction between titanium matrix and the addition of $\mathrm{LaB}_{6}$ powder. Fig. 2 shows the SEM image of the $\mathrm{La}_{2} \mathrm{O}_{3}$ particles obtained by backscattered electron. The particle size ranged widely from $\sim 30 \mathrm{~nm}$ to $1 \mu \mathrm{m}$. The matrix was constituted by equiaxed $\alpha$ phase and $\beta$ phases. As received micro and nano-sized $\mathrm{La}_{2} \mathrm{O}_{3}$ particles are distributed at the $\alpha / \beta$ phase boundaries.

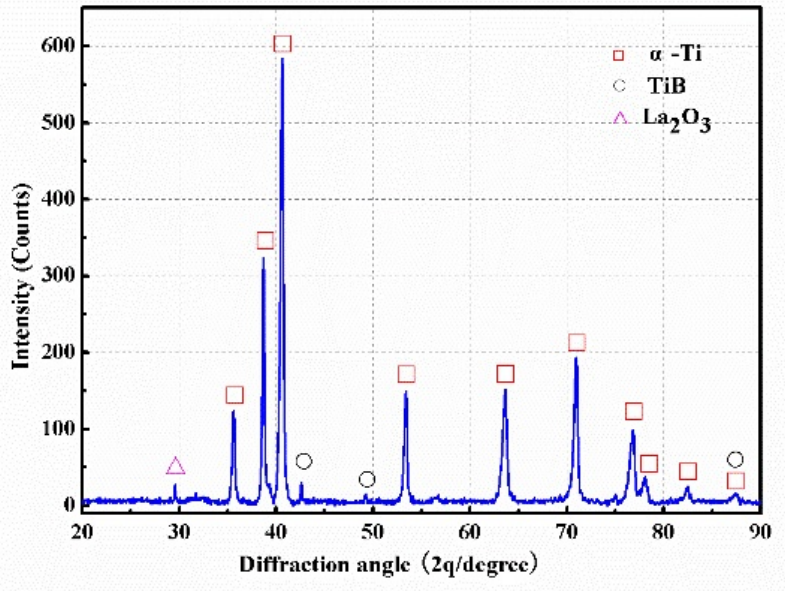

Fig. 1 X-ray diffraction pattern of the deformed TMCs

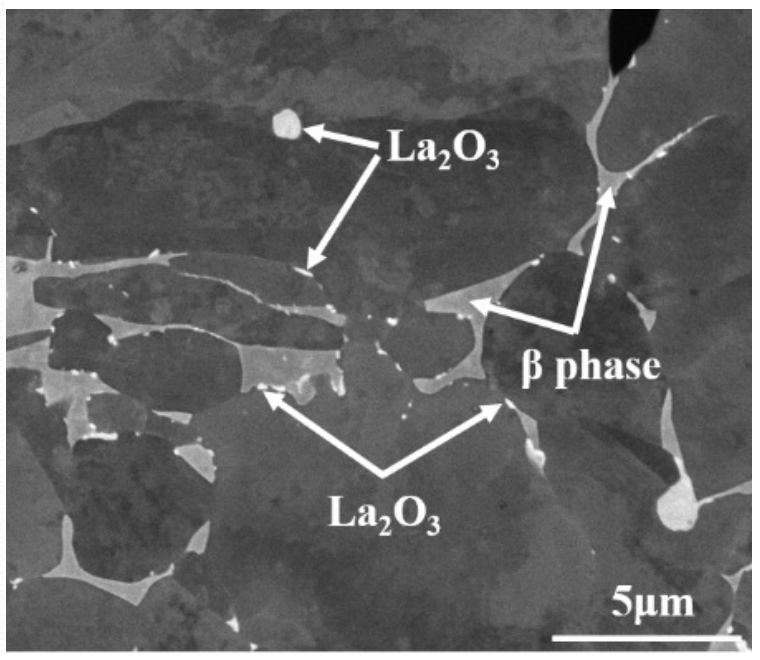

Fig. 2 SEM image of the $\mathrm{La}_{2} \mathrm{O}_{3}$

3.2 Microstructural evolution

To obtain the optimal processing window in the deformation of TMCs, the microstructure of $\left(\mathrm{TiB}^{\mathrm{B}} \mathrm{La}_{2} \mathrm{O}_{3}\right) / \mathrm{Ti}$ composite deformed at different temperature $\left(850^{\circ} \mathrm{C} \sim 1100^{\circ} \mathrm{C}\right.$ ) are investigated in Fig. 3 . It is clear to found that all a phases are elongated along the deformation direction, and the TiB fibers are aligned to the compression direction (In Fig. 3a and 3b). Both the elongated a phase and TiB whiskers are aligned perpendicular to the compression direction, and a majority of TiB fibers distribute in the vicinity of the transformed $\beta$ phase. The $a$ phase is much harder than the $\beta$ phase, so the soft $\beta$ phase deforms more easily than the hard $\alpha$ phase under the compression force, causing that TiB fibers tend to rearrange along the flowing of $\beta$ phase. Moreover, the breaking of TiB whiskers and the interfacial debonding between TiB and the matrix can be observed (In Fig. 3a and 3b). This phenomenon can be explained as the stress concentration in the vicinity of TiB fibers caused by the rapid increase of 
dislocation density and the in-coordinate deformation between TiB and matrix at low temperature and high strain rate. It is indicating that inhomogeneous deformation in the matrix also demonstrates the unsuitable domain for $\left(\mathrm{TiB}+\mathrm{La}_{2} \mathrm{O}_{3}\right) / \mathrm{Ti}$ composites to deform at $<950^{\circ} \mathrm{C}$. In addition, Fig. $3 \mathrm{c}, 3 \mathrm{~d}$ and $3 \mathrm{e}$ present the microstructure of the deformed TMCs processed in the $\beta$ phase region. The matrix was composed of lamellar a phases and short TiB fibers in a good interfacial bonding. Few microscopic cracks were observed in the TiB short fibers of TMCs. The lamellar thickness was much thicker in the samples deformed at a high temperature, while resulted in a spheroidized microstructure. It could be inferred that the deformation temperature affected the microstructural evolution in the $\beta$ phase region.
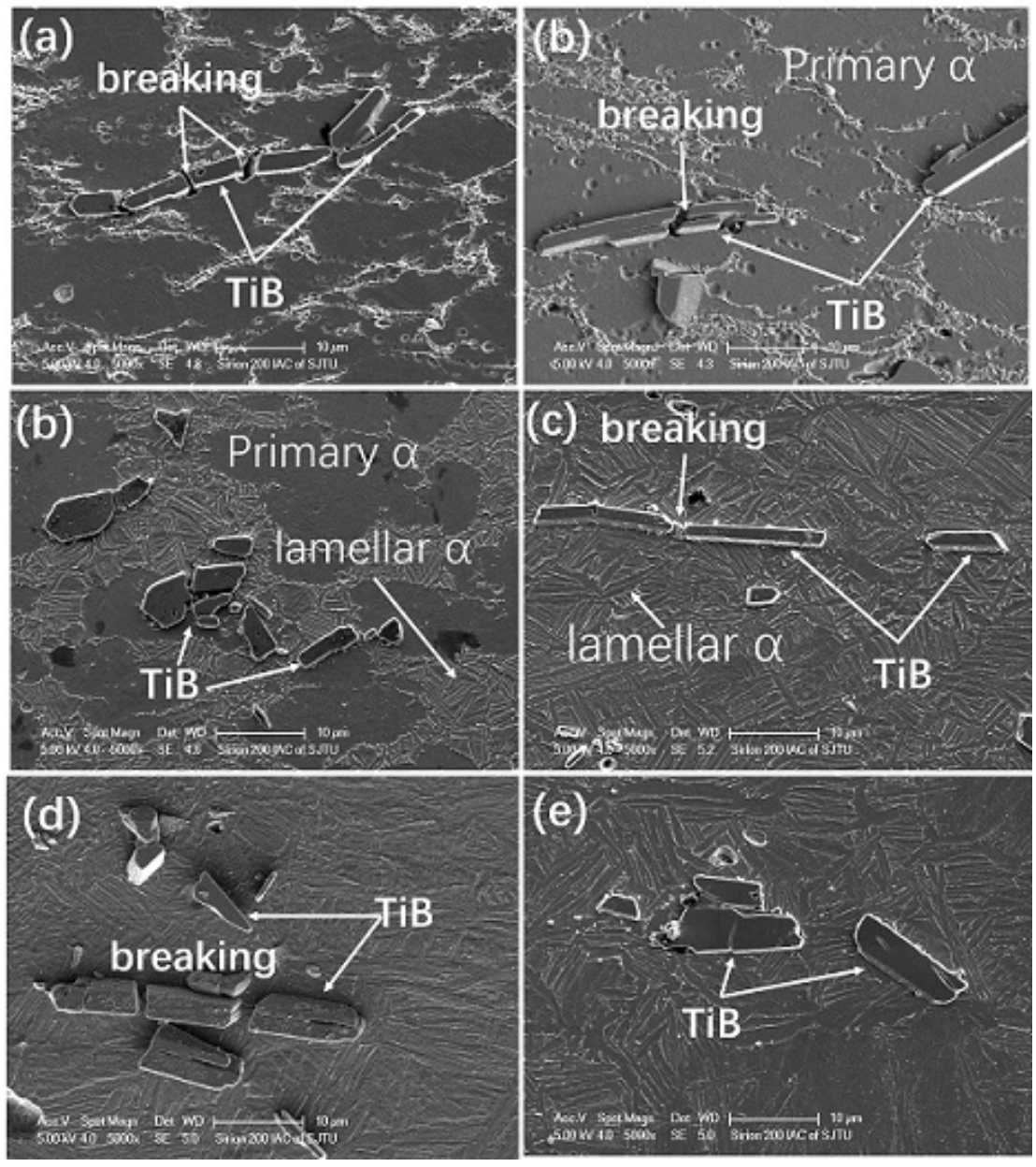

Fig.3 The microstructure of $\left(\mathrm{TiB}+\mathrm{La}_{2} \mathrm{O}_{3}\right) / \mathrm{Ti}$ composite deformed at different temperature

(a) $850^{\circ} \mathrm{C} / 1 \mathrm{~s}^{-1}$ (b) $900 / 1 \mathrm{~s}^{-1}$ (c) $950^{\circ} \mathrm{C} / 1 \mathrm{~s}^{-1}$ (d) $1000 / \mathrm{s}^{-1}$ (e) $1050^{\circ} \mathrm{C} / 1 \mathrm{~s}^{-1}$ (f) $1100^{\circ} \mathrm{C} / 1 \mathrm{~s}^{-1}$

Fig. 4a-4d shows the SEM image of the deformed structure of the compressed samples at strain rate of $0.001 \mathrm{~s}^{-1}, 0.01 \mathrm{~s}^{-1}, 0.1 \mathrm{~s}^{-1}$ and $1 \mathrm{~s}^{-1}$, respectively. The microstructure of the reinforced Ti matrix consists of equiaxed a phase with few intergranular $\beta$ phases (Fig.4a), which is typical since the matrix metal deformed slowly below the $\beta$ transus temperature. While as the strain rate rises, an increase in the proportion of acicular a phases can be observed in the intergranular $\beta$ phases (Fig.4b), smaller primary a phases and acicular a principally constitute the microstructure of the reinforced TMCs. The formation of acicular a is ascribed to the adiabatic temperature during the high strain rate deformation caused by the low thermal conductivity of Ti matrix. However, it is not clear if this effect can be attributed to the presence of TiB reinforcements, since the boron is a-stabilizing component. Furthermore, lots of lamellar a phase decrease in the length of ranging from $7 \mu \mathrm{m}$ to $3 \mu \mathrm{m}$ as well as an increase in the fraction of lamellar a is observed with increasing strain rate. The phenomenon is related to the generation of a large number of defects in transformed $\beta$ phase during high strain rate deformation, which provides more nucleation sites for lamellar a during phase transformation. As a consequence, both the high nucleation density and insufficient time for lamellar growing ultimately result in forming the shorter lamellar $a$ at high strain rate. But such variation in the phase proportion 

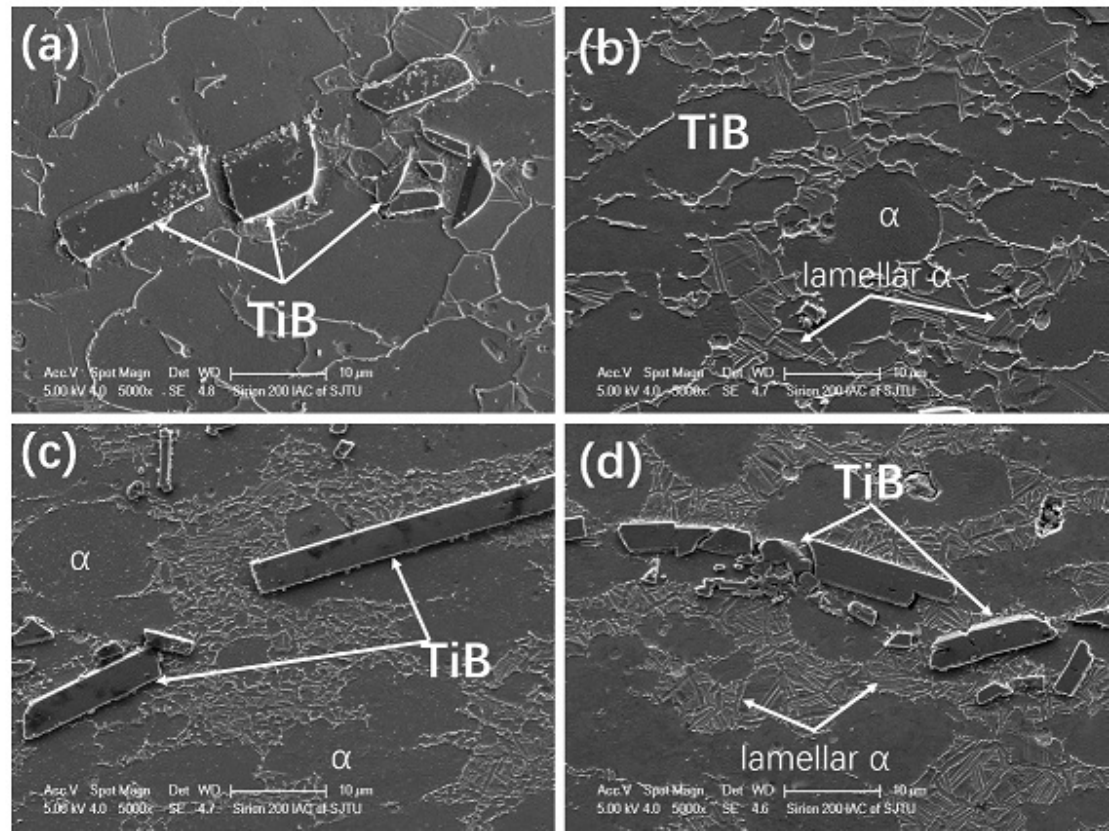

Fig.4 The microstructure of $\left(\mathrm{TiB}+\mathrm{La}_{2} \mathrm{O}_{3}\right) / \mathrm{Ti}$ composite deformed at $950^{\circ} \mathrm{C}$

(a) $0.001 \mathrm{~s}^{-1}$ (b) $0.01 \mathrm{~s}^{-1}$ (c) $0.1 \mathrm{~s}^{-1}$ (d) $1 \mathrm{~s}^{-1}$

\section{Discussion}

4.1 Lamellar globularization

EBSD technique was applied to further investigate the microstructural evolution of the composite in $\alpha+\beta$ phase region, as shown in Fig.5. Large number of fine dynamically recrystallized (DRXed) grains can be observed, and the drastic grain refinement is produced by the DRX process in equiaxed primary a grains. In Fig. $5 \mathrm{a}$ and $5 \mathrm{~b}$, a large quantity of low-angle grain boundaries (LAGBs) and high-angle grain boundaries (HAGBs) distribute in primary a grains. It seems that new DRXed grains in primary a are developed by the in situ evolution of subgrains with the growth of LAGBs to HAGBs, which is associated with the typical continuous dynamic recrystallization (CDRX) mechanism. Furthermore, the globularization of a phase can be explained by the formation of interphase $a / a$ boundaries or localized shear bands across the a plates. As shown in Fig. 5b, lots of HAGBs can be observed in the vicinity of primary a grains, reflecting that lamellar a gradually evolved into the spheroidized lamellar structures during hot deformation process, which indicates that the dynamic globularization of lamellar a is activated by the evolution of LAGBs to HAGBs, rather than the localized shear bands. Subsequently, the penetration of transformed b phase along the HAGBs, driven by the higher boundary energy of HAGBs within lamellar a, results in the transformation of a lamellar microstructure into globularization. 

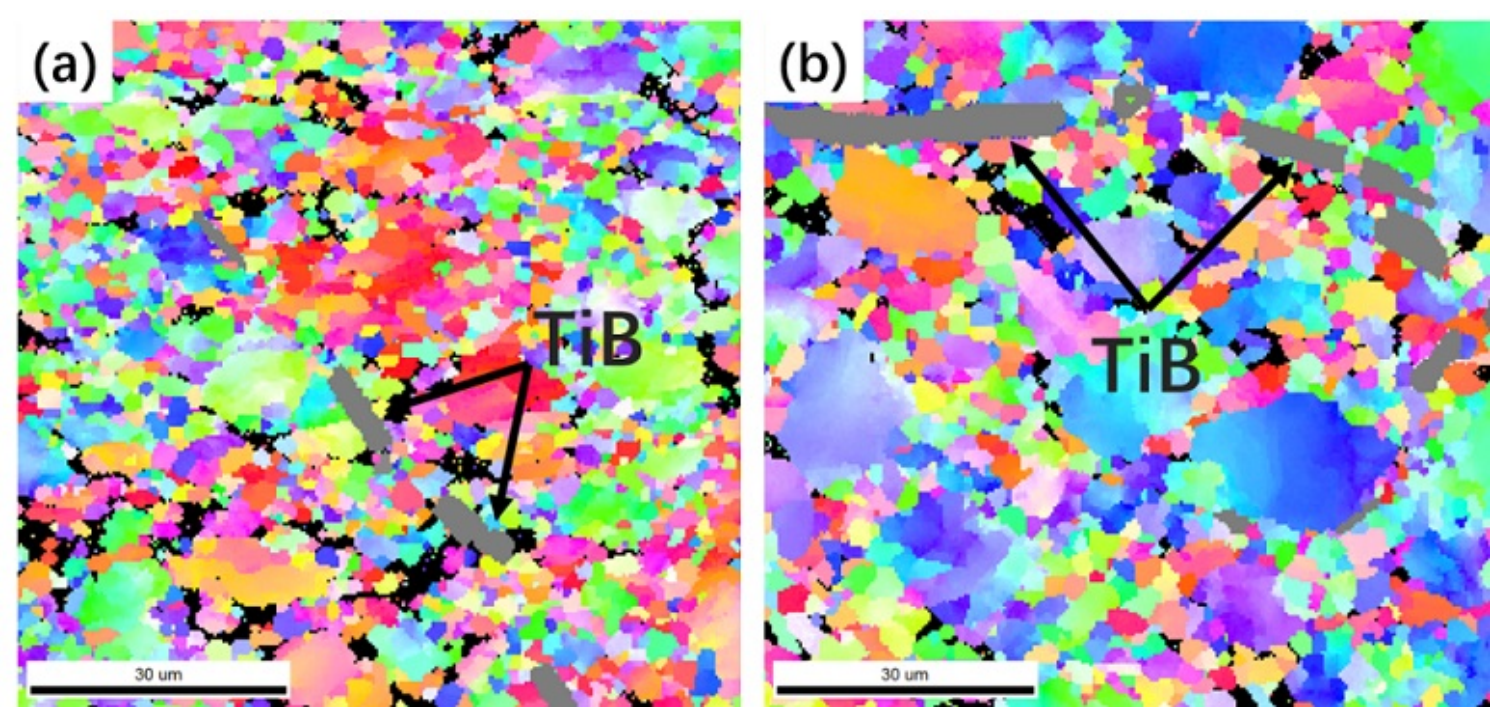

Fig.5 EBSD results of $\left(\mathrm{TiB}+\mathrm{La}_{2} \mathrm{O}_{3}\right) / \mathrm{Ti}$ composites: inverse pole figure (IPF) map at (a) $900{ }^{\circ} \mathrm{C} / 0.01 \mathrm{~s}^{-1}$, (b) $950^{\circ} \mathrm{C} / 0.01 \mathrm{~s}^{-1}$.

4.2 Role of the TiB/nano-sized particles

Fig. 6 presents the TEM observations of the reinforcements deformed in $\alpha+\beta$ phase region. The TEM observations indicated that lots of dislocations accumulate in front of the TiB fibers and $\mathrm{La}_{2} \mathrm{O}_{3}$ particles, and a high density dislocation originated in the intergranular $\beta$ phases near the lamellar boundaries. The La $\mathrm{O}_{3}$ particles are approximately $500 \mathrm{~nm}$. These reinforcements were micro $\mathrm{TiB}$ and submicro $\mathrm{La}_{2} \mathrm{O}_{3}$. It is obvious that the micro-sized TiB fibers provide obstacles for the deformation of composite, and work hardening was enhanced by the dislocation pile-up and tangling around these reinforcements, resulting in a higher strength. Though the dislocations would pass the small size $\mathrm{La}_{2} \mathrm{O}_{3}$ particles, it was playing a pinning role in the grain boundary movement and induced dynamic recrystallization. As it could be observed, the TiB fibers not only induced higher strength, but also the formation of dynamic recrystallized grains. The $\mathrm{La}_{2} \mathrm{O}_{3}$ particles also contribute the high resistance to deformation for the composite through dispersion strengthening.
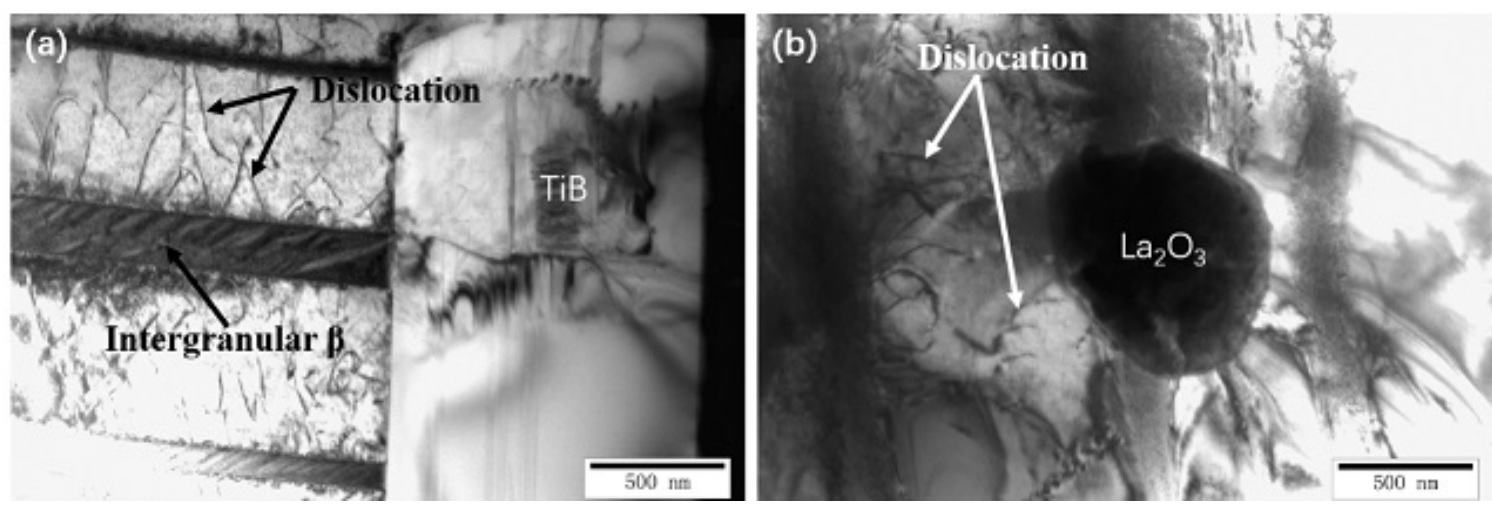

Fig.6 TEM observation of the deformed Ti composites: dislocation in front of (a) TiB fibers and (b) $\mathrm{La}_{2} \mathrm{O}_{3}$ particles

4.3 Fracture mechanism

Fig. 7 shows the typical features of the fracture surfaces observed in the studied TMCs with reinforcement content (2.5 Vol. and 5 Vol. \%). The transgranular fracture is a predominant mode of failure demonstrate that the Ti composite exhibit low ductility at room temperature. Higher content ( 2.5 vol. \% and 5 vol. \%) brings about more broken reinforcements and defects, which result in brittle fracture in Ti composite. Reinforcements and defects are believed to be the key factors to determine the crack propagation. Intergranular cracking is the main cracking way in the region where there are few reinforcements. Defects caused by fractured TiB play a dominant role in diverting intergranular cracking to transgranular cracking. Once a crack is initiated with the direction coinciding with the crack propagation direction, it can easily propagate 
through the whole grains and TiB fibers and $\mathrm{La}_{2} \mathrm{O}_{3}$ particles. Additionally, the decrease of the average length of TiB fibers with increasing content also affected the mechanical properties of deformed TMCs markedly (As shown in Fig. 7c and 7d). Interfacial bonding between the TiB short fibers and matrix would lead to high stress concentration at the tips of TiB, and cracks will preferentially originate in such areas. As shown in Fig.7d, high TiB content would produce much more cracks during the deformation, which creates favorable condition for crack propagation in TMCs. Simultaneously, it should be note that all TiB fibers show fractured cross-sections, this could be the fact that TiB fibers predominately orient longitudinal to the deformation direction. Thus, the cross-section of TiB will be revealed in the fracture surface. No TiB fibers and $\mathrm{La}_{2} \mathrm{O}_{3}$ are pulled out from the Ti matrix, indicating that strong interface cohesion existed between the reinforcement and matrix. In addition, numerous small La $\mathrm{O}_{3}$ particles along the phase boundaries and matrix-TiB interface are formed during the propagation of the main crack. The fracture behavior of the $\left(\mathrm{TiB}^{\mathrm{B}}+\mathrm{La} \mathrm{O}_{3}\right) / \mathrm{Ti}$ composite is strongly dependent upon the random orientation.
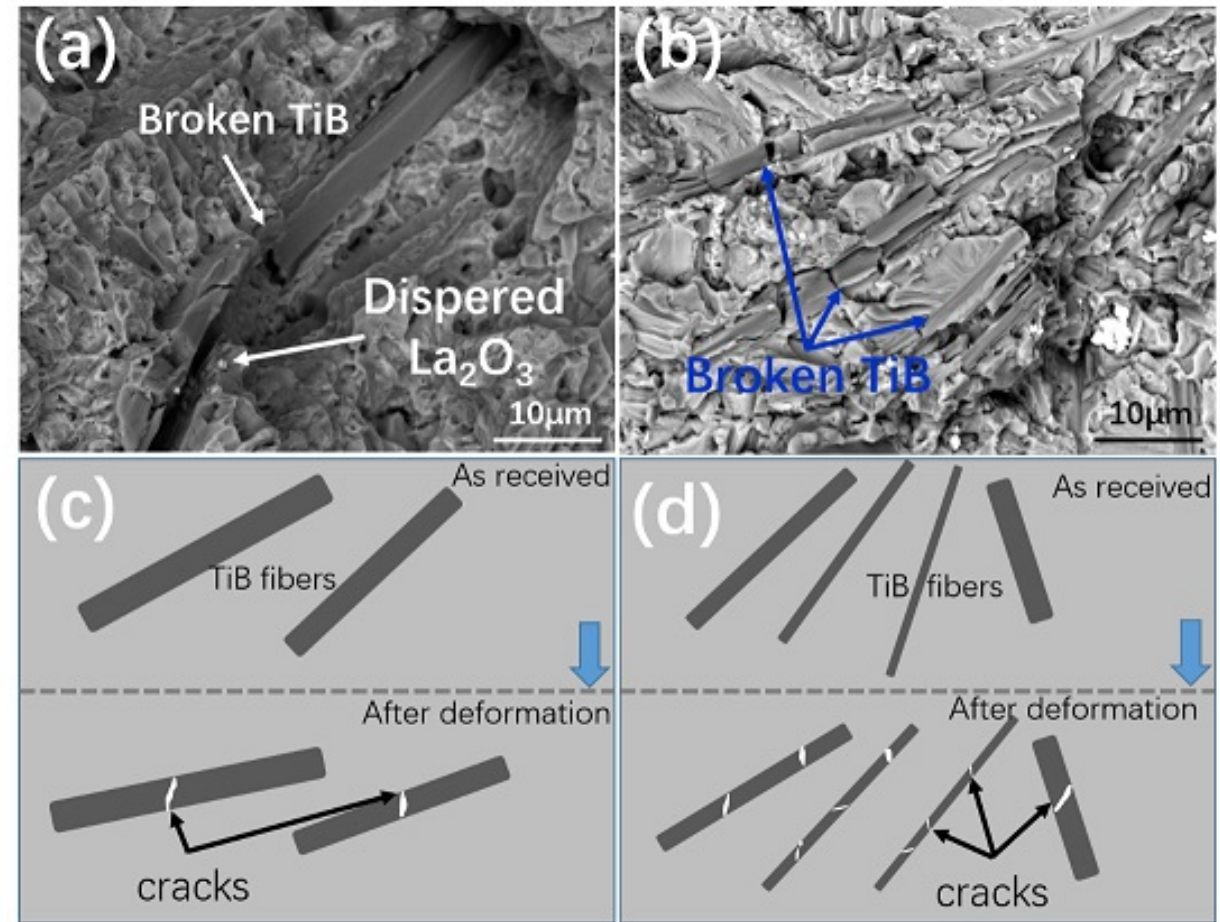

Fig.7 Fracture mechanism of TMCs with different reinforcement content

(a) 2.5 Vol. \% (b) 5 Vol. \% (c) low TiB content (d) high TiB content

\section{Conclusion}

Titanium matrix composites reinforced by in situ synthesized TiB-La $\mathrm{O}_{3}$ were hot working at the range of $850^{\circ} \mathrm{C}-1100^{\circ} \mathrm{C}$ and strain rate of $0.001 \mathrm{~s}^{-1}-1 \mathrm{~s}^{-1}$. The effect of processing parameters, the initial microstructure and resultant hybrid $\mathrm{TiB}_{\text {and }} \mathrm{La}_{2} \mathrm{O}_{3}$ on the deformation mechanisms were examined. Several conclusions can be drawn from this study.

(1) The optimal working parameters for the Ti composites is determined at $900-950^{\circ} \mathrm{C} / 0.01-0.1 \mathrm{~s}^{-1}$, which is associated with the continuous dynamic recrystallization of primary a grains and dynamic globularization of lamellar a.

(2) TiB fibers and $\mathrm{La}_{2} \mathrm{O}_{3}$ nano-sized reinforcements play indispensable roles in microstructural evolution during hot working. TiB and La $\mathrm{O}_{3}$ can impede dislocation movement, which results in work harden around the phase interface. Simultaneous, TiB fibers can facilitate the dynamic recrystallization of a phases and grain refinement. 
(3) Higher TiB content brings about more broken reinforcements and defects, which result in brittle fracture in Ti composite, defects caused by fractured TiB play a dominant role in diverting intergranular cracking to transgranular cracking.

(4) The obtained optimal processing parameters suggested that the present deformation routes might be effective for titanium matrix composite reinforced with hybrid $\mathrm{TiB}+\mathrm{La}_{2} \mathrm{O}_{3}$ reinforcements, which incorporating with plastic deformation in the temperature of $\alpha+\beta$ region. It can be apparently considered for engineering application.

\section{Acknowledgements}

This work was supported by National Nature Science Foundation of China (Grant No: U1602274, 51875349, 51871150, 51821001), the Aeronautical Science Foundation (Grant No: 20173625005), Shanghai Science and Technology Committee Innovation Grant (17JC1402600), the Equipment Pre-Research Foundation (41422010509, 61409230409) and the 111 Project (Grant No. B16032).

\section{References}

[1] C.J. Boehlert, S. Tamirisakandala, W.A. Curtin, D.B. Miracle, Assessment of in situ TiB whisker tensile strength and optimization of TiB-reinforced titanium alloy design, Scr. Mater. 61 (2009) 245-248.

[2] S.C. Tjong, Y.W. Mai, Processing-structure-property aspects of particulate and whisker-reinforced titanium matrix composites, Compos. Sci. Technol. 68 (2008) 583-601.

[3] P. Qiu, H. Li, X. Sun, Y. Han, G. Huang, W. Lu, D. Zhang, Reinforcements stimulated dynamic recrystallization behavior and tensile properties of extruded $\left(\mathrm{TiB}+\mathrm{TiC}+\mathrm{La}_{2} \mathrm{O}_{3}\right) / \mathrm{Ti} 6 \mathrm{Al} 4 \mathrm{~V}$ composites, J. Alloys Compd. 699 (2017) 874-881.

[4] W.J. Lu, D. Zhang, X. Zhang, R.J. Wu, T. Sakata, H. Mori, HREM study of TiB/Ti interfaces in a TiB-TiC in situ composite, Scr. Mater. 44 (2001) 1069-1075

[5] K. Geng, W.J. Lu, D. Zhang, Microstructure and tensile properties of in situ synthesized $\left(\mathrm{TiB}+\mathrm{Y}_{2} \mathrm{O}_{3}\right) / \mathrm{Ti}$ composites at elevated temperature, Mat. Sci. Eng. A, 360 (2003) 176-182.

[6] J. Li, L. Wang, J. Qin, Y. Chen, W. Lu, D. Zhang, Effect of microstructure on high temperature properties of in situ synthesized $\left(\mathrm{TiB}^{\mathrm{B}} \mathrm{La}_{2} \mathrm{O}_{3}\right) / \mathrm{Ti}_{\mathrm{i}}$ composite, Mater. Charact. 66 (2012) 93-98

[7] I. Sen, S. Tamirisakandala, D.B. Miracle, U. Ramamurty, Microstructural effects on the mechanical behavior of B-modified Ti-6Al-4V alloys, Acta Mater. 55 (2007) 49834993.

[8] L.Q. Huang, L.H. Wang, M. Qian, J. Zou, High tensile-strength and ductile titanium matrix composites strengthened by TiB nanowires, Scr. Mater. 141 (2017) 133-137

[9] P.W. Liu, Y.F. Han, P.K. Qiu, F.S. Xu, Y. Chen, L.H. Du, W.J. Lu, Isothermal deformation and spheroidization mechanism of $\left(\mathrm{TiB}^{\mathrm{L}} \mathrm{La} \mathrm{O}_{2} \mathrm{O}_{3}\right) / \mathrm{Ti}_{\mathrm{c}} \mathrm{composites}$ with different initial structures Materials Characterization 146 (2018) 15-24

[10] P.K. Qiu, H. Li, X.L. Sun, Y.F. Han, G.F. Huang, W.J. Lu, D. Zhang, Reinforcements stimulated dynamic recrystallization behavior and tensile properties of extruded $\left(\mathrm{TiB}+\mathrm{TiC}+\mathrm{La}_{2} \mathrm{O}_{3}\right) / \mathrm{Ti} 6 \mathrm{Al} 4 \mathrm{~V}$ composites, J. Alloys Compd. 699 (2017) $874 \mathrm{e} 881$

[11] Z.F. Yang, W.J. Lu, L. Zhao, J.N. Qin, D. Zhang, Microstructure and mechanical property of in situ synthesized multiple-reinforced (TiBtTiCtLa2O3)/Ti composites, J. Alloys Compd. 455 (2008) 210-214. 